\title{
Environment Charge and Covid
}

\author{
Katarina Vavrová1, ${ }^{*}$ Miloš Bikár ${ }^{1}$ \\ ${ }^{1}$ University of Economics in Bratislava, Faculty of Business Management, Dolnozemská 1, 85235 \\ Bratislava, Slovak Republic
}

\begin{abstract}
The primary goal of the paper is to examine the trends of global development and also global changes in the context of selective excise taxes, which are part of the Slovak tax system. First, it is necessary to describe the theoretical research, for clarity in this topic. To this end, we will provide an overview of developments in excise duties and environmental taxes. We will also focus on key events in the global economy that have had an impact on the formation of the Slovak tax system and also on legislative changes in the field of selective excise taxes. Next, we focus on the specification of the main goal of the paper. We will further specify the mathematical and statistical methods used. The result of the paper represents the latest legislative changes that are relevant from our point of view. In the next part of the article, we are going to examine the financial results of the company in connection with the applied environmental policy. In the last part of the article, we summarize the most important findings of our analysis and also point out the impacts of the environmental policy applied by the state on the indicators of green growth in the time of Covid.
\end{abstract}

\section{INTRODUCTION}

Manufacturing companies strive to make the highest possible profits and do not think about the future in relation to the environment. Countries are also trying to solve this unfavorable situation through taxes. Environmental taxes are key tools for achieving sustainability in the economy by increasing the prices of environmentally harmful goods or the cost of production inputs. Developed countries, such as the European Union, have recently been drawing more and more attention to this area of the economy.

Growing concerns about climate change are putting environmental issues at the forefront of the economic agenda in many European countries. Global warming is one of the most important challenges facing the world [1]. Taxes, fees, tradable permits and other economic instruments play an important role in achieving cost-effective control of greenhouse gas emissions. Their potential scope and revenues increase the much broader implications of economic and fiscal policy. European countries introduced carbon taxes in the 1990s, although the draft European energy tax was ultimately unsuccessful. Recently, the focus has been on emissions trading. Several tax measures have been introduced in the EU, in particular with environmental objectives. They included national environmental

\footnotetext{
* Corresponding author: katarina.vavrova@euba.sk
} 
taxes along with the existence of environmental tax measures. The increasing use of environmental taxes, emissions trading and other economic instruments was partly conditioned by the recognition of the limitations of conventional environmental regulation. They can initiate the necessary changes in the economy, resource use, behavior and general approach to nature [2]. The relationship between environmental knowledge, attitudes and behavior is complex. In addition, electricity consumption in the six Gulf Cooperation Council countries has increased rapidly in recent decades due to rapid population growth and relatively rapid economic growth [3]. Energy is an integral part of our daily lives in a market economy society. We need it for heating, cooling, lighting and movement; it is important for the functioning of our offices, workplaces and the whole economy [4]. This is one of the reasons why the EU Commission has proposed its Energy Union Strategy.

\section{Data and methods}

The main object of our analysis is the company Mondi SCP, a. s., operating in the territory of the Slovak Republic. As the subject of the company's activity is the production of paper and pulp, it is a suitable object for the implementation of our research, which we want to primarily determine the degree of involvement of the company in environmental protection and the consequences of this activity on the achieved financial results. Another subject of the survey can be considered the Slovak Republic, specifically in the field of taxation of its entities and also the European Union, which consisted of 28 member states, as in the analyzed period was also part of the United Kingdom. It is also a comprehensive source of information on the state and development of the environment and related aspects for the general public [5]. The Slovak Environmental Agency processes and regularly evaluates various sets of indicators [6]:

\section{- Sustainable Development (TUR) indicators. \\ - Green growth indicators, environmental indicators. \\ - Resource efficiency indicators.}

To obtain current data, we also drew from the OECD library, where several publications focused on the topic of environmental policy of states, tax policy in general, as well as data on the effects of the coronavirus pandemic on taxation were published. We also drew information from articles in professional journals and from scientific papers. Data related to changes in legislation were available on the MFSR website. We had quantitative data on the development of selective excise duties within the Slovak Republic and the European Union at our disposal thanks to the EUROSTAT database, which falls under EU control. Financial data of Mondi SCP, a. with. we drew from the published financial statements. Information on implemented projects was specified on the company's website and in published annual reports. We obtained data for the analysis of green growth indicators of the country from the DATACUBE database published by the Statistical Office of the Slovak Republic. The procedure for the calculation of indicators is published by the Ministry of the Environment of the Slovak Republic. From the Ministry of Economy of the Slovak Republic, we obtained data for quantifying the efficiency of energy consumed by Mondi SCP. Based on the analysis of indicators and regular evaluation of the European Environment Agency (EEA) [7], the evaluation options of the Organization for Economic Development and Economic Cooperation (OECD) and of the European Union Office of Indicators (Eurostat) were evaluated. Flexible and liquid markets can enable supply and demand to be more efficiently adjusted, reducing production costs and therefore prices. Such situations should also trigger bilateral contract prices in the most developed markets [8]. To interpret the obtained data, we mainly used descriptive statistics, through which we divided the quantum 
of data into clear tables and graphs. We mainly used quantitative indicators in absolute terms. For a clearer illustration of the relationships between quantities, in some cases we considered it appropriate to use the share of individual parts in the whole. We also used the method of comparison, specifically we compared data for different time periods. Within the analyzed company, we looked for an analogy between the procurement of equipment relevant from an ecological point of view and the achieved results of the company in the area of costs, revenues and emissions of harmful substances into the air. Looking at selective excise taxes as part of the Slovak tax system, we looked for an analogy between the development of this type of taxes and global changes. To express the company's performance, we used relative profitability indicators, which are part of the ex-post analysis. To express the development of $\mathrm{CO} 2$ emissions produced into the air in the company after the introduction of more environmentally friendly technology, we expressed by means of a moving average. Its positive is mainly the exclusion of random influences from time series. Only after this adjustment is it possible to objectively assess the data. The charts also includes a forecast based on historical data. We also used time series for the chronological arrangement of the sequence of comparable values, while applying the longterm periodicity of their monitoring. The analysis allowed us to select the most important ones from the amount of available data. Through synthesis, on the other hand, we assessed their interrelationships.

\subsection{Environmental charge, indicators}

In this part of the paper we will analyze the individual environmental charges from a theoretical point of view. Indicators are measurable quantities that provide information on the development and trends of phenomena and processes from a quantitative and qualitative point of view. In terms of indicators, the basic aim of research is to identify key environmental indicators that reliably reflect environmental policy. The basic starting point for their identification was environmental indicators obtained from data of individual sectors (selective excise tax trends). Environmental taxes are one of the most important instruments of the European Union's environmental policy.

\section{- Sustainable Development (TUR) indicators.}

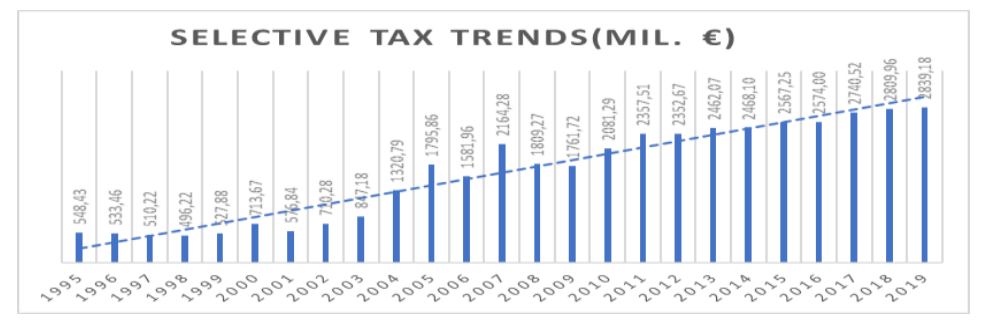

Fig.1. Selective tax trends in Slovac republic, 1995 -2019. Source: Eurostat

Their values ranged from 548.43 mil. EUR (in 1995) and 2,839.18 mil. $€$ (in 2019). This significant difference is also due to the fact that energy taxes were at the level of $0 \%$ until 2007 , and starting this year, the total value of revenues began to exceed the level of 2,000 mil. EUR. In addition, a green energy tax was introduced in 2010.

- Green growth indicators, environmental indicators. 


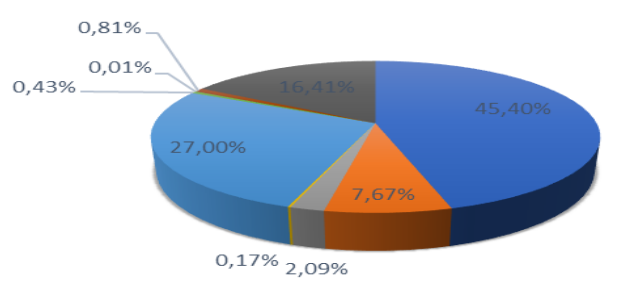

Fig. 2. Structure of revenues from selective excise taxes in the Slovak Republic (2019).

Source: Eurostat

The chart shows that almost half, namely $45.40 \%$ of total revenues are accounted for by mineral oil tax revenues, which also dominated in the previous monitored periods. The second highest share falls on taxes levied on tobacco and tobacco products at $27 \%$. This item can also be considered important as its share in total revenues has consistently exceeded the level of $20 \%$ since 1995 and its value has been constantly growing from 1995 to 2004 , this growth was accompanied by fluctuations in subsequent periods. The last item, the value of which was above the level of $10 \%$ (16.41\%) in 2019, was the tax on green energy. As we have already mentioned, this was the last tax introduced from the category of excise duties, although, as we can see, it represents a significant part of revenues. Its share of excise revenue has doubled in the last 10 years. The opposite trend can be observed for the alcohol tax, which accounted for $16.25 \%$ in 1995 and is currently at around $7.67 \%$. The percentages of other types of excise duties are below 3\%, with the lowest share of coal tax at $0.01 \%$.

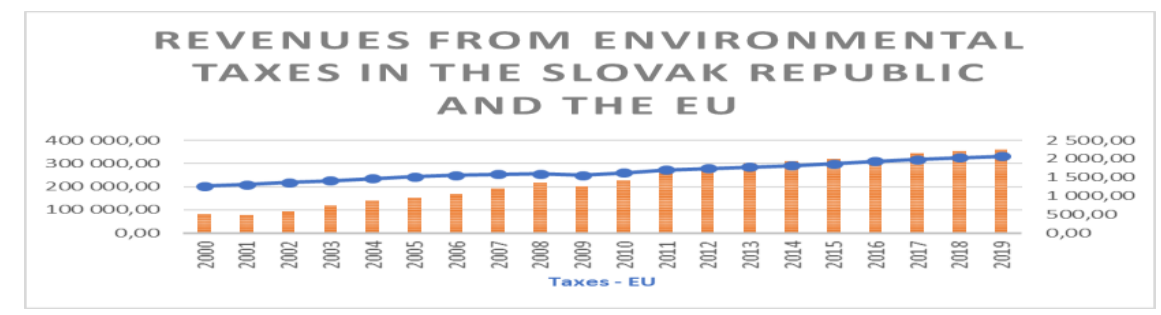

Fig. 3. Trends in European Union, electricity prices. Source: Eurostat

In the European Union, the value of these revenues in 2019 reached the level of 389,406.79 mil. EUR, while in the Slovak Republic revenues amounted to 2,245.98 mil. EUR. In the European Union, the value of these revenues in 2019 reached the level of 389,406.79 mil. EUR, while in the Slovak Republic revenues reached 2,245.98 mil. EUR. Current results cannot be analyzed due to a pandemic Covid. As economic growth has slowed significantly and even stopped production altogether for some time, we expect its effects to be significant.

\section{- Resource efficiency indicators, implementation of environmental measures.}

The basic starting point for their identification was environmental indicators obtained from data of individual sectors (selective excise tax trends). The picture shows the development of total revenues from this tax category. Over the last ten years, total EU environmental tax revenues have increased between 2008 and 2019. Data show that total EU environmental tax revenues are increasing [9]. The justification for revenue growth stems from rising 
environmental tax rates. Exceptions to this rising trend are 2007 and 2009, during which Europe went through a global financial crisis [10]. Environmental taxes are closely linked to the effective tax rate.

The chart also shows the effective tax rate, which is calculated as the ratio between the income tax and the company's profit, which we found before tax. The difference between the income tax and the actual tax rate arises when items such as permanent, temporal or other differences and the tax credit are taken into account. It may be affected by changes in statutory income tax rates.

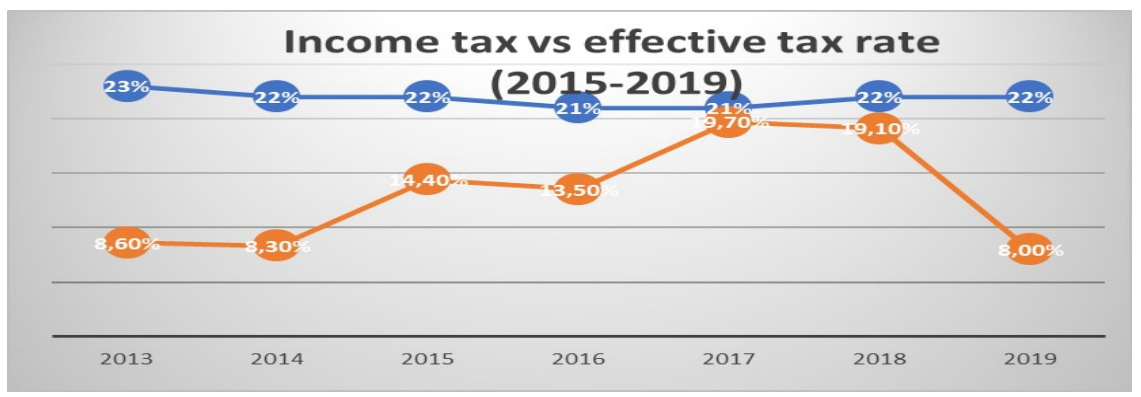

Fig. 4. Income tax vs effective tax rate (2016 - 2019).

Source: own processing based on data from: www.registeruz.sk

The OECD uses income data provided annually by correspondents from national ministries of finance, tax administrations or national statistical offices [11]. Although preliminary data are available for most countries with a lag of about six months, finished data are available with a lag of about one and a half years. Final data on income for 2017 were received in the period May - August 2019. In OECD countries, the reported year coincides with the calendar year. This will be achieved through flexible recruitment procedures designed to attract quality candidates, a focus on training and the development and development of systems that capture and enable best practice to be repeated. As they say, globalization is also one of the most important facts [12]. The modern trend in tax agencies is for more highly skilled workers who have merit based on merit and performance management and development systems [13]. In the context of energy consumption, the issue of greenhouse gas emissions needs to be addressed. For the development of emissions, we have compiled a graph that interprets the results of the moving average of emissions for the period from 2013 to 2019.

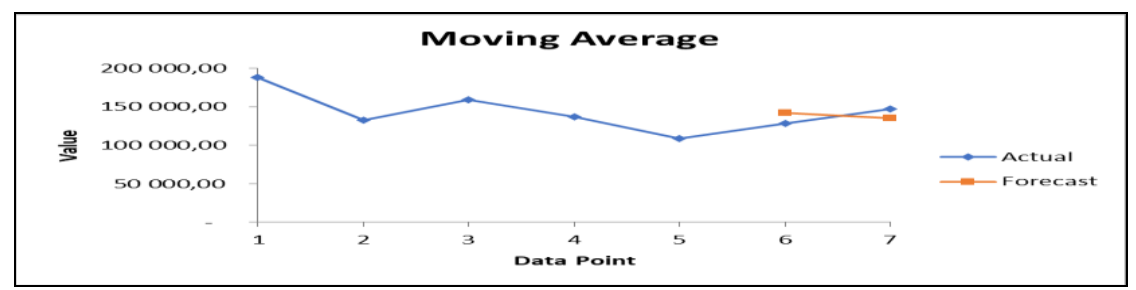

Fig. 5. Moving average of CO2 emissions in Mondi SCP, a. with. (2013 - 2019)

Source: own processing based on data from: https://www.mondigroup.com/en/sustainability/

Mondi SCP, a. with. after its latest investment in a renewable boiler, it is $100 \%$ a selfsufficient company in the field of energy production, with up to $94 \%$ of it coming from renewable sources. It is essential for society to pay attention to climate change. The climate crisis is affecting the company's operations and supply chain, through effects on water, weather, carbon regulation and taxation, energy availability and price. Increasing self- 
sufficiency in energy production contributes to improving energy profitability and security. The production of pulp, paper and packaging is energy-intensive, with energy generation being one of the main sources of greenhouse gases. The highest decrease compared to 2013 was recorded in 2017 , when the value of emissions was up to $42 \%$ lower than before the introduction of the recovery boiler.

\section{Results and Discussions}

Environmental charges are used to influence the behavior of economic operators, whether producers or consumers. The EU favors these instruments because they provide flexible and cost-effective means. The use of economic instruments for the environment is promoted in the EU Environment Action Program 2020, the EU's Sustainable Development Goals and the Europe 2020 Strategy. Economic instruments for pollution control and natural resource management are an important part of environmental policy in EU Member States [ 14]. Environmental indicators, together with those supporting the Europe 2020 strategy, continue a series of important Eurostat publications in support of the Europe 2020 strategy by monitoring progress towards the objectives set under the three mutually reinforcing priorities of smart, sustainable and inclusive growth. The analysis is based on the Europe 2020 headline indicators selected to monitor progress towards the strategy's objectives. Other breakdowns focusing on specific subgroups of society or the economy are also used to deepen the analysis and provide more detailed information. The data come mainly from official statistics compiled by the European Statistical System and published by Eurostat. To support this statement, we present graph no. 7, which shows data on year-on-year growth, resp. decline in GDP at constant prices, $\mathrm{CO} 2$ and $\mathrm{CO} 2$ productivity, which we have quantified as the ratio between GDP and CO2 emissions. It is evident that in 2009 there was a year-on-year decrease in both GDP and CO2 emissions, which resulted in an increase in the value of the $\mathrm{CO} 2$ productivity indicator. However, in the following year 2010 we can already see an increase in the volume of production. The increased activity of economic entities was also reflected in the increased volume of produced harmful emissions. In the following years, fluctuations can be observed, from 2014 to 2017, even a decline in greenhouse gas productivity, which evokes that the state's environmental policy would probably need to be reconsidered. However, in 2018, for which we had the latest data, we can observe an increase in the value of the indicator. The positive impact was mainly due to the higher volume of gross domestic product in absolute terms than the volume of $\mathrm{CO} 2$ emissions, while $\mathrm{CO} 2$ emissions recorded a significant year-on-year decrease.

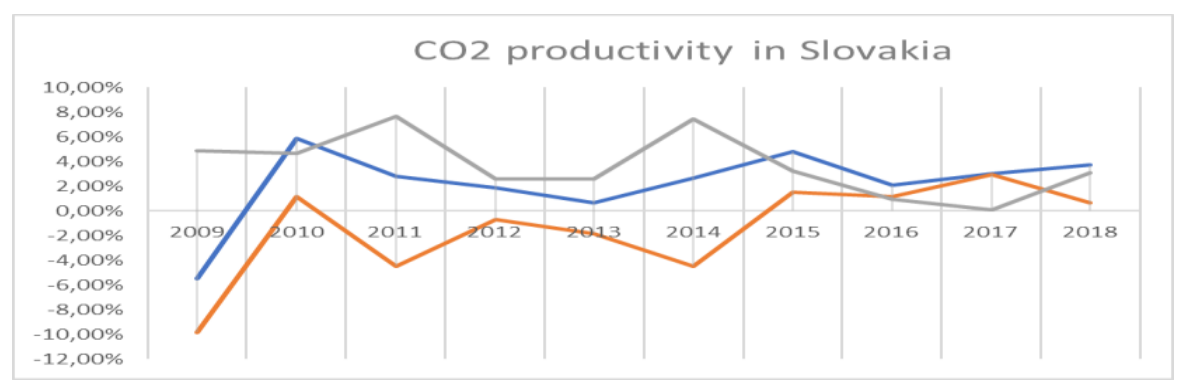

Fig. 6. Total environmental taxes in countries European Union (mill. Eura). Source: Eurostat 


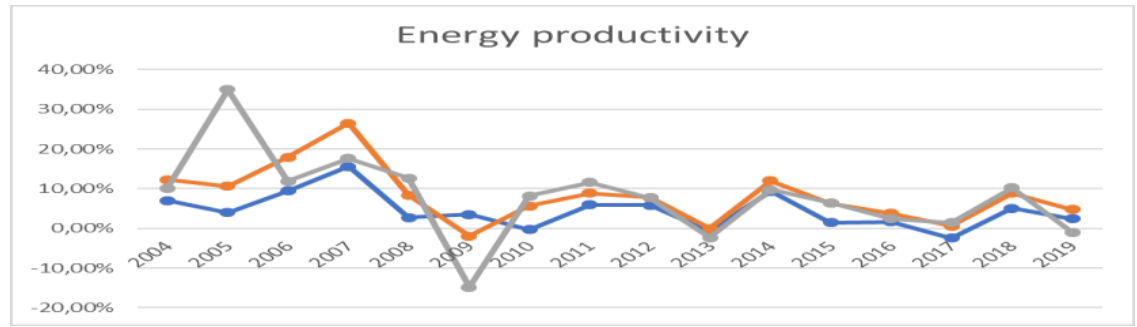

Fig. 7. Total energy production in countries European Union (mill. Eura). Source: Eurostat A similar indicator is energy efficiency, which represents the share of energy consumption in gross domestic product. We can observe a similar development, in 2009 there was a year-on-year increase in energy efficiency. In the context of environmental indicators, needs considered in energy. Primary energy production is any extraction of energy products in a usable form from natural sources [15].

\section{Conclusion}

Our claims are supported by the fact that, after each global crisis, the economy has recovered, accompanied by increased production, which has led to a renewed increase in gas emissions. The proof is the following picture:

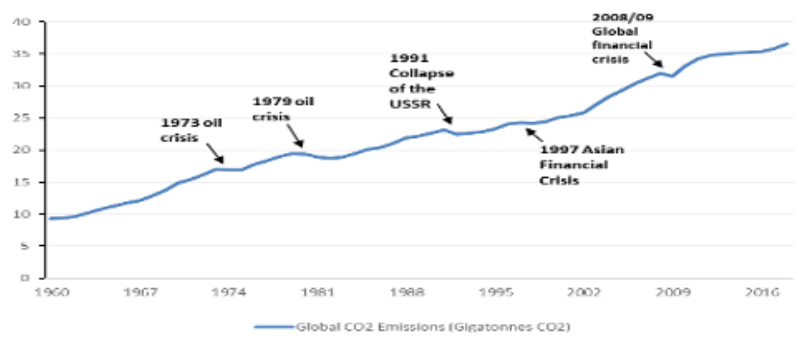

Fig. 8. Impact of economic crises on $\mathrm{CO} 2$ emissions. Source: Eurostat

Great competition is a reality. The market has changed, competitiveness is higher. Slovak manufacturing companies must carefully monitor changes in the market and respond to the requirements of domestic and international markets. In particular, they must consider meeting the conditions in foreign markets [17]. Businesses must also focus on the environmental side of production [16]. they must consider digitization production and logistics [18].

\section{Acknowledgment}

The presented working paper is the output of the scientific grants VEGA n. 1/0007/19 "Allocation of assets in the environment of low interest rates in financial and non-financial corporations in Slovakia" in the range of $100 \%$.

\section{References}

1. N. Suwirman, Environmental Altruistic Behavioral. International Journal of Environmental Research and Development 4, 1 (2014)

2. F. Aidyn, Secondary school students' perceptions towards global warming: a phenomenographic analysis. American Journal of Nursing Science, Essays 5, 2328 (2017) 
3. J.M. Hines, H.R. Hungerford, A.N. Tomera, Analysis and Synthesis of Research on Responsible Environmental Behavior: A Meta-Analysis. The Journal of Environmental Education 18, 1 (2010)

4. J. Squalli, Electricity consumption and economic growth: bounds and causality analyses of OPEC members. Energy Economics Journal 29, 1192 (2007)

5. C. Fischer, W.H. Parry, W.A. Pizer, Instrument choice for environmental protection when technological innovation is endogenous. Journal of Environmental Economics and Management 45, 523 (2003)

6. Energy, transport and environment statistics 2019 edition, The Statistical books, Eurostat, Printed by Imprimeries Bietlot Freres in Belgium, European Union, (2019).

7. I. Ioannou, G. Serafeim, What drives corporate social performance, International evidence from social, environmental and governance scores. Journal of International Business Studies 43, 834 (2012)

8. P. Deng, A. Delios, M.P. Pemg, A geographic relational perspective on the internationalization of emerging market firms. Journal of International Business Studies 51, 50 (2020)

9. G. Tomas, M. Hult, M.A. Gonzalez-Perez, K. Lagerstrom, The theoretical evolution and use of the Uppsala Model of internationalization in the international business ecosystem. Journal of International Business Studies 51, 38 (2020)

10. M.A. Marinov, S.T. Marinova, J.A. Larimo, T. Lepovsky, Characteristics and Future Trends. Internetional Business and Emerging Economy Firms 1, 1 (2020)

11. J. Kwan Kim, R. Mudambi, An ecosystem-based analysis of design innovation infringements: South Korea and China in the global tire industry. Journal of International Business policy 3, 38 (2020)

12. M. Minárová, D. Malá, M. Sedliačiková, Emotional Intelligence of Manageres. 4th Conference on Business. Economics and Management Journal (WCBEM). Ephesus, Turkey 124, 1119 (2015)

13. J. H. Rogers, C. Scotti, J. H. Wright, Evaluating asset-market effects of unconventional monetary policy: a cross-country comparison. Journal Economic Policy 29, 749 (2014)

14. J. Dobrovič, A. Korauš, L. Dančišinová, Sustainable economic development of Slovakia: Factors determining optimal tax collection. Journal of Security and Sustainability Issuess, International Entrepreneurial perspectives and Innovative Outcomes 5, 533 (2016)

15. D. Youová, Environmental taxation. Brussels, [electronic source]. Available on the Internet: [cit. 2018-02-02]

16. K. Mc Cullagh, O. Tambou, S. Bourton, (Eds.), National Adaptations of the GDPR, Collection Open Access Book, Blogdroiteuropeen, Luxembourg, 1- 130 (2019)

17. K. Porubanová, K., P. Richnák, Usability of Intangible Assets in the Terms of Manufacturing Companies. Ad Alta. Journal Of Interdisciplinary Research, 7(2), 177 180 (2017)

18. A. Dupal', P. Richnák, L. Szabo, K. Porubanová, Modern Trends in Logistics of Agricultural Enterprises. Agricultural Economics, 65(8), 359-365 (2019) 